\title{
NOTA AL EDITOR
}

Iván Molina Jiménez

En el volumen 20, número 3, 2018, de Telos. Revista de Estudios Interdisciplinarios en Ciencias Sociales, fue publicado el texto titulado "Narrativas innaturales, ciencia ficción y neoliberalismo en Costa Rica", del señor Roy Alfaro Vargas, quien se presenta como un "investigador independiente". En dicho texto, el señor Alfaro afirma lo siguiente:

“'Un joven demonio entre las sombras' de Molina-Jiménez es un cuento que no se elabora dentro de una diégesis con tecnología futurista, ni con una crítica del establishment y, al contrario, se asienta dentro de una ideología fascista. Así, este cuento presenta a dos sicarios del Primer Mundo, que matan a un disidente (tercermundista), quien protesta contra los intereses de algunas empresas transnacionales. Este cuento afirma como valor el derecho a matar a quien se oponga al capital. Este cuento no es CF" (Alfaro Vargas, 2018: 479).

De manera complementaria, en la nota al pie número 7, el señor Alfaro indica lo siguiente:

"Es difícil entender cómo una universidad con principios humanistas (la Universidad Estatal a Distancia) publica un cuento con una ideología de este tipo, que atenta contra el legítimo derecho de los pueblos a la protesta. El derecho a la protesta es un derecho fundamental del ser humano, el cual no puede ser violentado por los intereses de las transnacionales y de los países del Primer Mundo" (Alfaro Vargas, 2018: 479).

La interpretación que el señor Alfaro hace del cuento carece de todo respaldo, ya que basta leer ese relato para constatar que no "se asienta dentro de una ideología fascista" ni "afirma como valor el derecho a matar a quien se oponga al capital". Precisamente

\footnotetext{
* Escuela de Historia y Centro de Investigación en Identidad y Cultura Latinoamericanas de la Universidad de Costa Rica. Autor de numerosos estudios sobre la historia de Centroamérica en general, y de Costa Rica en particular. Sus relatos de ciencia ficción han sido publicados en Estados Unidos, México, España, Colombia, Argentina, Perú, El Salvador, Nicaragua y Cuba. Costa Rica. Correo electrónico: ivan.molina@ucr.ac.cr
} 
porque el contenido de ese cuento no apoya en forma alguna la interpretación del señor Alfaro, él no puede ofrecer evidencia directa ni indirecta que sustente su argumentación. En consecuencia, lo que el señor Alfaro sostiene en relación con el cuento y con la Universidad Estatal a Distancia (UNED) son simplemente afirmaciones sin fundamento.

Con el propósito de distorsionar mi cuento y presentarlo como manifestación de una narrativa fascista, y de descalificar a la UNED por haberlo publicado, el señor Alfaro deliberadamente ocultó que hay otra interpretación de mi relato, la cual difiere significativamente de la suya. Se trata del análisis llevado a cabo por Yolanda MolinaGavilán, renombrada especialista en ciencia ficción latinoamericana y profesora en el Eckerd College (Florida). Molina-Gavilán (2015: xii-xiii) interpretó mi cuento en el marco de las relaciones desiguales de poder que existen entre los países desarrollados y en vías de desarrollo, sin indicar que mi cuento se posicione a favor de los países desarrollados. De hecho, Molina-Gavilán más bien sugiere lo contrario:

"Iván Molina Jiménez, con su mucho más político 'Un joven demonio entre las sombras', transporta al lector a Europa y a África. Los dos protagonistas de su relato, originarios respectivamente de unas militarizadas Alemania y Francia del futuro, resultan ser unos sicarios al servicio de una empresa de seguridad que tiene como punto de mira al líder de una huelga de trabajadores en Tanzania. Las sombras del título bien pudieran entenderse como las que se ciernen sobre los países en vías de desarrollo, explotados económicamente a manos de un primer mundo necesitado de recursos naturales y que aplica fríamente su superioridad armamentística".

Así, en vez de rebatir los argumentos de Molina-Gavilán, el señor Alfaro optó por ocultarlos. Su proclividad a ocultar información relevante, también se constata en la bibliografía de su texto. Pese a que el señor Alfaro se auto-referenció generosamente (de 63 referencias bibliográficas, casi el 20 por ciento son suyas), de manera deliberada omitió una referencia fundamental: un artículo en el que el Dr. David Díaz Arias (2015), Director del Centro de Investigaciones Históricas de América Central de la Universidad de Costa Rica (UCR), cuestiona decisivamente sus 
interpretaciones de la ciencia ficción costarricense. De acuerdo con Díaz, el señor Alfaro

"reproduce los estereotipos europeizantes y estadounidenses que tanto ha costado derrumbar a los estudiosos de la ciencia ficción latinoamericana. Así, quizás sin saberlo, Alfaro hace eco de un histórico prejuicio cultural imperial: despreciar lo producido en las periferias del capital y mirarlo como no ciencia ficción, así como en el pasado, ese mismo prejuicio cultural, ha servido para otros propósitos imperiales".

De nuevo, en vez de rebatir los argumentos de Díaz, el señor Alfaro prefirió ocultarlos, práctica que repitió una vez más al mencionar (Alfaro Vargas, 2018: 470) una discusión que tuvo conmigo:

"Asimismo, se debe señalar que el volumen 40, número 1, de la Revista de Filología y Lingüística que recoge tales artículos, también incorpora el texto de Alfaro-Vargas (2014a), escrito (por invitación) desde una perspectiva críticomarxista, el cual desató una discusión iniciada con la participación de MolinaJiménez (2014) y Alfaro-Vargas (2014c), extendiéndose esta desde finales del 2014 hasta mediados del 2015".

Primeramente, conviene aclarar, con respecto al texto que el señor Alfaro afirma haber escrito "por invitación", las condiciones en que se produjo esa “invitación”. Según el Dr. Carlos Manuel Villalobos (2018), quien en el año 2014 era Director de la Escuela de Filología, Lingüística y Literatura de la Universidad de Costa Rica, dicha unidad académica lo que hizo fue una invitación abierta a todas las personas interesadas en presentar propuestas para un dossier sobre literatura fantástica, no fue una invitación expresamente extendida al señor Alfaro para que escribiera sobre el tema.

Ahora bien, al referirse a la discusión que tuvo conmigo, el señor Alfaro citó solo dos referencias -"Molina-Jiménez (2014) y Alfaro Vargas (2014c)" (Alfaro Vargas, 2018: 470)- y decidió omitir una tercera: aquella en la cual indiqué que el señor Alfaro es dado a criticar instituciones y personas de manera desproporcionada, infundada e infamante, al extremo de imputar que la renombrada novelista costarricense Ana cristina Rossi es una reaccionaria al servicio del Banco Mundial, 
implicar que todo el Departamento de Filología de la UCR es corrupto y acusar de corrupción al sistema de Régimen Académico de esa misma institución de educación superior (Molina Jiménez, 2014). Esa referencia deliberadamente omitida expuso no solo las debilidades epistemológicas del señor Alfaro, sino también sus falencias éticas, ya que sus textos, al distorsionar datos y ocultar información, no respetan las más elementales reglas del trabajo científico.

Agradezco a la editora de Telos por darme el derecho de responder al texto del señor Alfaro y así cumplir con el deber de promover la discusión académica de los artículos publicados en su revista. También reconozco su interés para que esta nota fuera publicada lo antes posible.

\section{Referencias bibliográficas}

Alfaro Vargas, Roy. (2018). Narrativas innaturales, ciencia ficción y neoliberalismo en Costa Rica. Telos. Revista de Estudios Interdisciplinarios en Ciencias Sociales. Volumen 20, número 3. Venezuela. (Pp. 468-491).

Díaz Arias, David. (2015). Tres prejuicios sobre la ciencia ficción costarricense. Revista Paquidermo. Costa Rica Extraído de: https://revistapaquidermo.com/archives/11306 Consulta: 02/10/2018.

Molina-Gavilán, Yolanda. (2015). Presentación. Te voy a recordar. Relatos de ciencia ficción. Editorial Universidad Estatal a Distancia. Costa Rica.

Molina Jiménez, Iván. (2014). Revistas académicas y responsabilidad universitaria. La Nación. Costa

Rica.

Extraído

de:

https://www.nacion.com/opinion/foros/revistas-academicas-y-responsabilidaduniversitaria/VQUPXO6CRJDSBETQOIBXECFUV4/story/

Consulta: 02/10/2018.

Villalobos, Carlos Manuel. (2018, octubre 2). Comunicación personal. Costa Rica. 